\title{
Arisan Sebagai Gaya Hidup (Sebuah Kritik Terhadap Masyarakat Konsumtif Perkotaan)
}

\author{
Varatisha Anjani Abdullah \\ Staf pengajar di jurusan Sastra Indonesia, \\ Universitas Pamulang, Tangerang Selatan. \\ Email:varatisha.anjani@gmail.com
}

\begin{abstract}
Abstrak
Studi ini bermaksud mengkaji fenomena gaya hidup di masyarakat perkotaan, khususnya Jakarta melalui kegiatan arisan. Penelitian di lakukan di daerah Jakarta pinggiran, tepatnya di daerah Ciputat, Tangerang Selatan. Dari penelitian yang dilakukan, ditemukan bahwa identitas merupakan hal yang penting di dalam kegiatan arisan. Identitas kemudian muncul karena kegiatan arisan yang ada didominasi oleh pola-pola konsumsi di dalmnya. Dari kegiatan konsumsi itu, lahirlah sebuah kompetisi antar anggotanya untuk menunjukkan siapa yang memiliki identitas lebih tinggi dan siapa yang tidak. Sang ketua arisan memunyai pengaruh besar dalam memengaruhi para anggotanya untuk mengikuti segala perintahnya dengan dalih kepentingan kegiatan arisan. Kekuatan ini tidak disadari oleh para anggota. Jalinan pertemanan yang kuat antara sang ketua dan anggotanya yang lain, membuat mereka masuk ke dalam sebuah sistem di mana ada yang mengendalikan dan apa yang dikendalikan.
\end{abstract}

Kata kunci : konsumerisme, arisan, identitas

\begin{abstract}
This study observed urban lifestyle phenomenon in Jakarta, namely arisan. Conducted in the outskirt of Jakarta, which is Ciputat, South Tangerang. This study, which aimed to observe the phenomenon of life style through arisan activities, attempted to observe ideas that underlies the motives of individuals when participating in arisan group and when consuming goods in their daily life. The study found that identity was important in arisan. It emerged as arisan activities were dominated by consumption. Competition among the members of arisan group occurred as a result. It showed who had higher identity and who had not. The role of the leader of the group was interesting as well. The leader was succesful to persuade the members to follow her orders for the sake of arisan activity. The power of the leader was not realized by other members. Strong bond of friendship between the leader and the members made them entering a system where one controlled others on what needs to be controlled.
\end{abstract}

Keywords: consumerism, arisan, identity 


\section{Latar Belakang}

Arisan merupakan bagian dari kegiatan sebagian kelompok masyarakat Indonesia, terutama kaum perempuan. Arisan bukanlah hal baru untuk kaum perempuan Indonesia. Arisan merupakan istilah yang digunakan untuk menyederhanakan satu konsep mengenai salah satu sistem regulasi keuangan, khususnya di Indonesia. Rotatting Saving and Credit Association (ROSCA) atau yang kenal dengan istilah arisan merupakan salah satu format yang menarik sebagai sebuah lembaga keuangan yang ada di wilayah pedesaan (Kern, 1986 dalam Hospes, 1992: 371).

Arisan merupakan sistem regulasi karena di dalamnya ada aturan-aturan bagi para anggotanya. Regulasi tersebut kemudian menjadi sistem yang mengatur segala aktivitas terkait dengan uang yang dikelola di dalamnya. Dahulu, arisan menjadi salah satu sarana bagi warga desa untuk menabung. Namun, hal ini dirasa tidak cukup efisien karena orang harus menjadi anggota terlebih dahulu untuk bisa menabung di dalamnya (Hospes, 1992: 373). Asosiasi kredit dan tabungan atau arisan ini tetaplah hanya lembaga keuangan sederhana yang lebih dilandaskan pada saling percaya. Arisan tidak cukup kuat untuk menjadi agen pembangunan sehingga akan tetap menjadi lembaga keuangan informal yang cenderung statis dan tidak mempengaruhi pembangunan di suatu negara (Eibel dan Marx, 1987 dalam Hospes, 1992: 373).
Saat ini, arisan mengalami perkembangan, baik dari jenis maupun bentuk kegiatannya sendiri. Arisan tidak lagi hanya dilakukan oleh perempuan perdesaan. Sebaliknya, di kota-kota besar, juga sudah marak oleh kegiatan arisan. Dilihat dari jenisnya, ada arisan yang tarikannya berupa uang seperti pada umumnya, tapi, seiring perkembangan jaman, ada arisan yang tarikannya berupa emas atau barang- barang mewah lainnya. Kemudian, jika dilihat dari kegiatannya, jika sebelumnya arisan dilakukan di rumah, maka saat ini para peserta arisan bisa berpindah dari satu ke tempat lainnya. Pilihan-pilihan atas tempat biasanya didasari pertimbangan kenyamanan. Faktor ini menjadi yang paling penting dalam mempengaruhi penentuan tempat. Kafe, mall atau lounge sebuah hotel merupakan tempat-tempat yang biasa dipilih untuk melakukan kegiatan arisan. Inilah yang menjadi salah satu daya tarik arisan untuk peneliti. Peneliti melihat arisan sebagai pintu masuk untuk mengkritisi gaya hidup masyarakat, sekaligus menjadi peluang untuk melihat dinamika identitas kelas menengah di Indonesia.

Di daerah Tangerang Selatan, tepatnya di Pamulang, terdapat satu kelompok arisan yang terdiri dari 13 ibuibu paruh baya. Mereka menamakan kelompok arisannya dengan sebutan 'Arisan Seleb'. Kondisi ekonomi mereka yang mapan, membuat kegiatan arisan ini menarik karena didominasi oleh kegiatan 
Varatisha Anjani Abdullah, Arisan Sebagai Gaya Hidup (Sebuah Kritik Terhadap Masyarakat Konsumtif Perkotaan)

yang dilakukan di luar rumah dan memerlukan uang yang tidak sedikit. Dalam kelompok 'Arisan Seleb' tersebut, arisan bukan menjadi kegiatan tunggal. Sebaliknya, arisan selalu diikuti kegiatan lainnya, yakni makan di restoran atau kafe mahal, karaoke, berbelanja, atau hanya sekadar traveling ke kota-kota di Indonesia. Untuk itu, mereka menyiapkan konsep dengan baik ketika hendak melaksanakan arisan.

'Arisan Seleb' itu sendiri berdiri sejak 2010. Sampai saat ini, 'Arisan Seleb' beranggotakan 13 orang. Mereka rutin bertemu setiap bulan. Artinya, dari 2010, mereka tidak putus mengadakan kegiatan arisan. Jika sudah habis pada kocokan ke 13, mereka akan memulai kembali dari awal dan seterusnya. Dengan demikian, sudah 5 tahun kelompok arisan ini berdiri dan bertemu setiap bulannya. Iuran arisan sebesar Rp. 1.500.000, dan dikocok di awal bulan. Tarif Rp. 1.500.000 ini berlaku sejak 2 tahun belakangan. Sebelumnya, besaran iuran Rp. 1.000.000. Angka ini cukup besar karena mereka sebagian besar hanya mendapatkan uang dari suaminya. Artinya, mereka bukanlah pekerja karir ataupun wiraswastawan.

'Arisan seleb' hanya salah satu perkembangan mutakhir arisan. Arisan yang dilaksanakan dalam lingkup tetangga sekitar atau lingkup RT atau RW masih ada. Namun, yang diproblematisasi dalam penelitian ini ialah bagaimana perkembangan arisan dari awalnya merupakan tabungan bergikir menjadi gaya hidup mutakhir di kalangan kelas menengah dengan jumlah pasokan yang besar.

Dalam ilmu sosial, gaya hidup (life style) merupakan sebuah cara bagaimana seseorang hidup. Menurut Assael (1984), gaya hidup adalah"A mode of living that is identified by how people spend their time (activities), what they consider important in their environment (interest), and what they think of themselves and the world around them (opinions)". Dari pengertian tersebut, dapat dikatakan bahwa gaya hidup merupakan bagaimana seseorang hidup, membelanjakan uangnya setelah kebutuhan primernya terpenuhi, serta bagaimana seseorang mengalokasikan waktu luang yang dimilikinya.

Erving Goffman dalam The Presentation of Self in Everyday Life (1959:40) mengemukakan bahwa kehidupan sosial terutama terdiri dari penampilan teatrikal yang diritualkan. Maksudnya, manusia bertindak sebagai aktor yang sedang memainkan sebuah lakon di atas panggung dimana lingkungan sosial yang ada di sekitarnya memiliki peranan sebagai penonton yang baik secara langsung ataupun tidak langsung ketika melihat pertunujukannya. Dalam kaitan ini, segala sesuatu yang dilakukan dan melekat pada dirinya itulah yang dipertontonkan di hadapan semua orang. Lalu, timbullah berbagai interpretasi atas apa yang dikenakan seseorang maupun yang dikonsumsinya. 
Interpretasi atas apa yang dipakainya itu menghasilkan pandangan mengenai kelas ataupun strata ekonomi. Inilah sebenarnya yang menjadi salah satu faktor mengapa orang berlomba-lomba untuk melakukan konsumerisme dan menunjukkannya kepada khalayak.

Kegiatan mengonsumsi menjadi hal yang sangat penting dalam masyarakat industri karena industrilah yang menyuplai kebutuhan gaya hidup seseorang atau satu masyarakat. Kondisi ini semakin jelas terlihat dalam masyarakat kapitalis dimana semua orang berhak menikmati kesenangan tanpa batas. Menurut Anthony Giddens (1991:198), proyek jati diri manusia kemudian diterjemahkan menjadi proyek pemilikan barang-barang yang diinginkan dan pengejaran gaya hidup yang dibingkai secara artifisial. Selain itu, pada masyarakat kapitalis, kegiatan mengkonsumsi barang-barang sebagai bagian gaya hidup dirangsang untuk keperluan sesaat.

Di Asia, menurut Chua Beng Huat (2000: 18), bentuk konsumsi menjadi berbeda terutama setelah resesi 1997. Menurut Chua, pasca 1997, nilai simbolik konsumsi menjadi penting di Asia. "The need to 'maintain' a lifestyle is all the more necessary for one of the newly rich to communicate to the world that is falling apart around him/her that he/she remains 'unaffected' and continues to be doing well economically, in hope of retaining the confidence of colleagues and business associates".

Masih menurut Huat, ritual keseharian telah bertransformasi menjadi gaya hidup yang berbeda dengan konsumsi barang atau jasa yang dapat dilihat sebagai munculnya 'orang kaya baru' di Asia, sebuah kelompok yang tersusun oleh kelas baru dari pebisnis dan kemunculan kelas menengah professional dan birokrat (Huat, 2000: 2).

Di Indonesia, menurut Solvay Gerke (dalam Chua. 2000: 135), demonstrasi simbolik kelas dan kelompok dalam gaya hidup terbentuk sebagai upaya demonopolisasi hierarki yang dulu didominasi oleh budaya kraton Jawa dan oleh golongan Neo-Priyayi dari pegawai sebelum rezim Orde Baru. Benih kelas menengah di Indonesia, menurut Gerke, telah muncul ketika pemerintah kolonial berada di Indonesia ${ }^{1}$. Munculnya NeoPriyayi dimulai ketika sekumpulan masyarakat pribumi yang bekerja di pemerintahan kolonial sebagai pejabat sehingga dengan berakhirnya masa kolonial, maka otomatis merekalah yang menduduki posisi-posisi pemerintahan dan dianggap memiliki pengaruh di masyarakat dan menjadi golongan baru, yakni Neo-Priyayi yang kemudian bertransfomasi menjadi kelas menengah. Jika Gerke melihat gaya hidup Indonesia

\footnotetext{
${ }^{1}$ Pandangan lain mengenai kelas menengah misalnya adalah kelas menengah dalam Islam dalam Heffner (1993 dalam Indonesia, Vol. 56 (Oktober 1993) pp 1-35)
} 
berakar dari dominasi kelas Kraton Jawa dan Neo-Priyayi, maka Heryanto (dalam Pinches. 1999: 160) mengemukakan bahwa kelas kaya didominasi oleh 'orang Barat' dan 'etnis China' (Chinese), kalaupun ada yang dapat ditambahkan adalah pegawai kelas atas pemerintah, meski ia berada di bawah kedua kelas tersebut. Berdasarkan latar belakang di atas, yang menjadi fokus penelitian ini adalah (1) bagaimana bentuk dan praktek konsumsi yang ada dalam 'Arisan Seleb' di setiap kegiatan yang mereka lakukan sehingga menjadi gaya hidup bagi setiap anggotanya?; dan (2) bagaimana dinamika relasi kuasa sang ketua arisan di Arisan Seleb dalam kegiatan mereka?

\section{Gated Community dalam Kelompok}

\section{'Arisan Seleb'}

Komunitas berpagar atau yang lebih dikenal dengan istilah Gated Community juga bisa menjadi pintu masuk ketika kita mau menelaah mengenai gaya hidup, khususnya masyarakat perkotaan. Gated Community merupakan bagian dari suburbanisasi (Blakely dan Synder, 1997 seperti dikutip Farida, 2008: 28). Kecenderungan ini muncul ketika pusat kota telah kehilangan posisinya sebagai tempat 'terkuat' dalam hierarki metropolis. Tangerang Selatan merupakan perluasan wilayah yang sebelumnya masih bagian dari Jakarta Selatan. Perkembangan infrastuktur yang luar biasa terjadi wilayah ini. Perguruan tinggi terkemuka hingga Bandara Udara
Soekarno Hatta kini ada di wilayahnya. Jakarta sebagai kota metropolitan tidak lagi menjadi pusat pembangunan infrastruktur. Bintaro, Serpong, Sentul, Depok hingga Tangerang Selatan kini berdiri menjadi kota yang mandiri lengkap dengan segala infrastrukturnya termasuk keberadaan komunitas berpagar ini.

Gated Community tumbuh sebagai akibat pengembangan perkotaan. Kondisi kota yang semakin tidak bersahabat dengan padatnya pembangunan yang berpusat di tengah kota, membuat sebagian masyarakat berpindah tempat tinggal ke daerah suburban yang memiliki potensi sebagai wilayah tempat tinggal yang lebih baik. Tujuh dari 13 anggota 'Arisan Seleb' tinggal di lingkungan perumahan yang sama. Mereka berkumpul di dalam satu komplek perumahan di kawasan Pamulang, Tangerang Selatan yang dapat dianggap sebagai kelompok Gated Community. Rani, yang merupakan ketua dari 'Arisan Seleb', ialah orang yang pertama kali tinggal di perumahan tersebut. Sudah hampir 20 tahun dia tinggal di situ lalu menyusul anggota arisan lainnya.

Di Indonesia, komunitas berpagar ini tumbuh dengan pesat. Namun, pertumbuhan ini justru membuat batasan persoalan sosial dan masalah keamanan yang ada di luar lingkungan tersebut. Komunitas berpagar di Indonesia dihuni oleh mereka yang bukan mewakili golongan kaya raya semata. Mereka juga 
berasal dari "kalangan menengah pekerja" yang mempunyai kecenderungan konsumtif dan gaya hidup mewah. Kesan eksklusif menempel pada identitas penghuni komunitas berpagar, tak terkecuali para anggota 'Arisan Seleb'.

\section{Munculnya Gated Community}

khususnya di Indoensia justru melahirkan fregmentasi kota (Blakely dan Snyder, 2003 seperti dikutip Widhyharto, 2009: 205). Rani dan kawan-kawan yang berasal dari kelas menengah atas pada akhirnya hanya menjalin keakraban dengan kelompok yang tinggal di situ dengan kondisi ekonomi yang tidak jauh berbeda. Rumah mereka menjadi pengejawantahan cerminan budaya, ras, kelas dan identitas para penghuninya. Rani yang bersuamikan seorang pejabat tinggi perusahaan kapal terbang milik negara akan nyaman tinggal di situ. Aset yang terlihat berupa 4 mobil miliknya akan terasa lebih aman jika ditaruh di lingkungan dengan keamanan tingkat tinggi karena minimnya akses keluar masuk bagi penghuni di sekitarnya.

\section{Arisan yang Telah Menjadi Gaya} Hidup

\section{Arisan Dahulu dan Sekarang}

Arisan bukan sebuah hal baru bagi masyarakat Indonesia. Dari awalnya, lekat dengan kehidupan kaum perempuan, terutama perempuan perdesaan. Bagi perempuan yang sudah menikah dan menjadi seorang ibu, perempuan tidak hanya bertanggung- jawab kepada anak-anak yang dilahirkan dengan baik, tetapi juga bahwa mereka bertanggungjawab kepada keluarganya yang lebih muda, baik secara usia maupun generasi yang ada di bawahya (Nihof, 1998: 245). Bagi perempuan yang menjadi bagian dari keluarga elit Jawa, seorang ibu juga dituntut untuk menjaga martabat keluarga. Tata krama dan sopan santun menjadi penting dijaga agar relasi sosial dan kekerabatan dengan keluarga elit lainnya tetap terjaga (DjajadiningratNieuwenhuis 1992 dalam Nihof, 1998:245).

Bagi ibu yang berada dalam kondisi ekonomi bawah, peranan ibu saat itu dibatasi untuk menjadi ibu yang baik dengan menjaga anak-anak mereka dengan baik pula (Nihof, 1998: 246). Peranan ibu mulai naik ke tingkat lokal desa tempat mereka tinggal melalui sebuah kegiatan yang disebut dengan PKK (Pembinaan Kesejahteraan Keluarga). Di PKK, perempuan akan diminta untuk mengambil bagian di kegiatan yang dianggap merupakan upaya pembangunan daerah tersebut. Dengan sukarela, mereka diminta untuk turut andil dalam kegiatan PKK, yang justru membuat mereka kehilangan waktu untuk mengurus keluarga khususnya anak-anak mereka. PKK menjadi sebuah ajang bagi mereka untuk keluar rumah dan berinteraksi dengan lingkungan sosial mereka. PKK juga yang menjadi salah satu ajang munculnya kegiatan arisan. Agenda arisan 
masuk menjadi salah satu menu yang ada di dalam kegiatan PKK.

Gotong-royong masih melekat pada kegiatan arisan terdahulu. Sebagai contoh, untuk membantu anggota keluarga yang sakit, para anggota arisan akan menyisihkan sedikit uang yang mereka miliki untuk membantu. Beban tarikan yang diputuskan akan menyesuaikan kemampuan para peserta dan akan diukur dari yang paling rendah sehingga tidak akan memberatkan para anggota. Ini karena kondisi ekonomi setiap warga di kampung berbeda-beda.

Perkembangan serta perbedaan signifikan terlihat jika arisan tersebut dibandingkan dengan saat ini. Kesederhanaan tidak lagi nampak pada kebanyakan kegiatan arisan. Kini, arisan bukan lagi sebagai ajang silaturrahmi, melainkan sebagai sebuah ajang atau arena pembentukan makna dan kelas. Pola-pola dan praktik konsumsi menjadi lebih dominan muncul dalam kegiatan arisan masa kini. Geertz (1962) yang meneliti Mojokuto pada 1950-an sudah menyadari bahwa bentuk-bentuk arisan akan berubah mengikuti perubahan struktur masyarakatnya.

Arisan kini menjadi sebuah gaya hidup masyarakat modern yang tumbuh dalam budaya konsumtivisme. Gaya hidup berkembang di dalam masyarakat yang diartikan melalui objek-objek material yang menjadi tolak ukur kelas sosial. Arisan sebagai sebuah praktik konsumsi dipandang bukan lagi sekadar sebagai pemenuhan kebutuhan hidup untuk bersosialisasi seperti yang diyakini Geertz (1962), juga tidak melulu sebagai instrument ekonomis untuk menabung (lihat Papanek dan Schweede 1988), tetapi arisan telah berkaitan pula dengan aspekaspek sosial budaya. Konsumsi yang terpola melalui kegiatan arisan berhubungan dengan masalah selera, identitas, dan gaya hidup.

Dalam kegiatan arisan, perputaran fashion menjadi kebutuhan. Setiap kegiatan itu berlangsung, setiap peserta berlomba-lomba menggunakan produk fashion terbaik. Mereka berada dalam pengetahuan fashion yang sama, yakni modis, up to date, dan glamor. Ini merupakan prinsip analisis tentang konsumsi, yakni ketika mentalitas konsumen bersifat individu dan kolektif (Baudrillard, 2009: 13). Hal ini sesuai dengan eksistensi diri manusia, yakni sebagai makhluk individu dan kolektif. Kodrat konsumen sebagai makhluk sosial menjadi dasar pertimbangan dalam berkonsumsi.

Gaya hidup, pilihan seseorang akan sebuah produk hingga hasrat mengkonsumsi seseorang, bukan hanya persoalan besar kecilnya pendapatan seseorang dalam kehidupannya seharihari. Hal tersebut tidak terlepas dari persoalan habitus dan persoalan persepsi sosial yang terstruktur. Oleh karena itu, perbedaan sosial yang terjadi dan berlangsung di masyarakat tidak serta merta disebabkan perbedaan kelas sosial 
yang ada di dalamnya, tetapi juga terbentuk karena bagaimana cara seseorang hidup atau habitus. Bourdieu (1986 dalam Paterson, 1997: 44) mengatakan bahwa habitus merupakan sebuah sistem di mana seseorang dikelilingi dengan keinginan, hasrat, dan pilihan akan cara-cara bagaimana mereka hidup sesuai dengan konstruksi sosial yang ada di lingkungan mereka. Habitus memang terbentuk dengan proses sosial yang panjang di dalamnya. Konstruksi yang terjadi di masyarakat terjadi berulang-ulang sehingga menjadi satu kebenaran yang kemudian menjadi kebiasaan di masyarakat.

Struktur menjadi hal yang penting dalam pembentukan habitus pada satu kelompok masyarakat. Struktur yang terbentuk kemudian menjadi habitus, lalu dijalani oleh masyarakat sebagai pola dalam kehidupan sehari-hari. Adanya agen juga menjadi aktor yang ikut membentuk habitus. Bordieu memakai konsep habitus untuk memahami struktur dan agen serta siapa yang ada di balik keduanya itu yang kemudian mampu mengkonfrontir sekelompok orang untuk memahaminya sebagai sebuah kebenaran.

Arisan merupakan salah satu alternatif kegiatan bagi seseorang untuk mengisi waktu luang yang dimilikinya. Karena itu, arisan dan leisure memiliki keterkaitan. Leisure sering diartikan sebagai perwujudan dari pelampiasan kesenangan/bersenang-senang. Jadi, leisure lebih diartikan sebagai kemampuan mengkonsumsi barang ataupun hal-hal yang berhubungan dengan praktek konsumsi untuk mengisi waktu luang yang ada.

Arisan menuntut setiap orang yang mengikutinya untuk memiliki waktu luang yang cukup banyak. Hal ini karena dalam sebuah kegiatan arisan, membutuhkan dan menghabiskan waktu yang cukup panjang. Rerata waktu yang digunakan 35 terbuang dalam setiap kegiatan arisan, bahkan bisa saja melebihi waktu rata-rata tersebut.

Uang, konsumsi, bersenangsenang merupakan hal-hal yang ada dalam lingkaran kegiatan arisan. Ini karena praktik-praktik konsumsi tersebut membentuk satu kesatuan dan terjadi berulang-ulang secara rutin yang kemudian harus dijalani oleh setiap orang yang mengikuti kegiatan tersebut jika tidak ingin dibilang berbeda oleh anggota kelompok arisan lainnya. Kegiatan arisan lazimnya dilakukan setiap 1-2 kali dalam satu bulan, tergantung kesepakatan kelompok. Dalam waktu itulah, setiap orang dalam kelompok arisan melakukan pola konsumsi yang hampir sama. Tema, tempat, baju seragam, model make up, aksesoris yang serupa merupakan sederet hal yang selalu hampir ada di setiap kegiatan arisan. Fashion merupakan hal yang tidak akan pernah lepas dari kegiatan ini. Sang ketua arisan yang memegang kendali menentukan itu semua. Ketua arisan memiliki peran untuk selalu update perkembangan fashion 
untuk kemudian diterapkan dalam arisan lalu diikuti oleh seluruh anggota arisan.

\section{Kuasa oleh Sang Ketua}

Di setiap kegiatan Arisan, selalu memiliki orang yang berperan sebagai ketua.Kontrol dan kendali adalah kata kunci dari peran sang ketua. Dia bisa mengontrol seluruh kegiatan arisan sesuai dengan apa yang telah dikonsepkannya dan bisa mengendalikan seluruh anggota untuk mengikuti instruksi mengenai tema, pakaian, aksesoris hingga tempat yang sesuai dengan keinginan Rani. Meskipun tetap ada ruang negoisasi antara sang ketua dengan para anggota, tapi tetap Rani memiliki suara yang lebih dominan dibanding anggotanya dalam anggota 'Arisan Seleb'. Bahkan, bisa dikatakan, Rani adalah orang yag paling punya kuasa dalam struktur kepengurusan Arisan Seleb dibanding yang lainnya.

Kuasa yang dimiliki oleh Rani memang masuk dan tumbuh secara perlahan dan tidak disadari oleh mereka yang ada dalam kelompok tersebut. Seiring berjalannya waktu dengan intensitas pertemuan mereka yang lumayan sering, membuat kuasa itu perlahan tumbuh dan menguat dalam lingkaran 'Arisan Seleb'. Inilah yang disebut sebagai soft power. Sebelum memahami soft power, terlebih dahulu perlu dipahami makna power atau kekuasaan yang kemudian mempengaruhi persepsi mengenai soft power itu sendiri (Chua Beng Huat, 2012: 119). Power dalam perspektif Weberian ialah kemampuan untuk bisa mempengaruhi seseorang untuk melakukan hal yang dia inginkan. Dalam hal ini, belum tentu hal yang dilakukan ialah hal yang disukai oleh subjek yang diberi perintah tersebut.

Chua memakai konsep soft power untuk melihat bagaimana Jepang, Cina dan Korea mempengaruhi dunia, khususnya Indonesia melalui produknya berupa tayangan drama, musik hingga produk fashion. Awalnya, soft power dilihat dalam konteks negara di mana negara mempengaruhi ideologi warganya melalui partai politik demi mendapat dukungan dan kekuasaan untuk memimpin negara. Konsep ini dikembangkan oleh seorang pengamat politik Amerika bernama Joseph Nye yang kemudian menjadi salah satu rujukan Chua dalam memakai konsep soft power (2000: 119).

Arisan yang dilakukan oleh kelompok 'Arisan Seleb' menjadi berbeda karena pola konsumsi yang ada di dalamnya. Arisan dengan skema sederhana yang dilakukan oleh ibu-ibu di kampung atau lingkup RT masih ada hingga kini, tpi kehadiran 'Arisan Seleb' menjadi warna tersendiri, khususnya bila ingin mengkaji kajian gaya hidup. Pola yang ada dalam kegiatan 'Arisan Seleb' akhirnya menjadi bagian dalam kehidupan mereka sehari-hari meskipun mereka tidak sedang berkumpul sebagai anggota 'Arisan Seleb'. Gaya hidup itu terbentuk karena selera kolektif yang 
terbangun dalam kegiatan 'Arisan Seleb' yang kemudian terbawa dalam kehidupan sehari-hari dan menjadi habitus. Selera tersebut mereka jaga dalam memilih benda-benda material untuk mempertahankan identitas mereka sebagai kelas menengah atas di ruang sosial yang ada di sekitar mereka.

'Arisan Seleb' merupakan sebuah sistem yang terbangun dari komunitas Gated Community. Rani dan kawankawan yang tinggal di kawasan yang sama ditambah lingkungan sekolah anak-anak mereka yang kemudian membuat kegiatan arisan menjadi semakin berwarna. Berangkat dari lokasi rumah mereka yang sebagian besar sama, tapi justru tempat anaknya bersekolah yang membuat hubungan mereka semakin akrab. Oleh karena anak-anak mereka bersekolah di tempat yang sama dan sekolah mahal, maka bisa dikatakan kemampuan ekonomi mereka setara. Kesetaraan itulah yang membangun atmosfer nyaman bagi siapa saja yang ada di dalamnya sehingga mereka merasa harus kembali melakukan adaptasi terhadap orang-orang di luar kelompok mereka. Kesetaraan itulah yang membuat hubungan mereka semakin erat.

Rani sebagai ketua kelompok 'Arisan Seleb' memiliki pengaruh luar biasa dalam dinamika kegiatan 'Arisan Seleb'. Pengaruh Rani yang besar telah berhasil menghasilkan kebijakankebijakan yang berlaku di 'Arisan Seleb' dan kemudian dipatuhi oleh seluruh anggota lainnya. Melalui kebijakannya,
'Arisan Seleb’ kemudian menjadi sebuah sistem di mana ada yang mengendalikan dan ada yang dikendalikan. Mereka seakan keluar dari sistem yang ada di kehidupan rumah tangga dan memiliki perasaan bebas karena bisa mengekspresikan diri melalui kegiatan yang mereka sukai. Tanpa mereka sadari, dengan tergabung dalam 'Arisan Seleb' di mana Rani bertugas sebagai ketua, mereka masuk ke dalam sistem lain bernama arisan di mana mereka harus mengikuti pola-pola dan kebijakan yang ditetapkan di kegiatan arisan tersebut. Sistem yang dibangun dan kebijakan yang lahir memang tidak disadari oleh para anggota lainnya. Hubungan emosional yang terbangun karena hubungan pertemanan yang sudah terjalin lama, membuat kekuasaan yang dimiliki Rani menjadi langgeng.

\section{Kesimpulan}

Penelitian mengenai perhasilkembangan arisan sebagai gaya hidup. Ada dua pertanyaan yang diajukan dalam penelitian ini, yakni perkembangan arisan sebagai gaya hidup dan relasi kuasa yang tumbuh dalam kelompok arisan. Studi dilakukan terhadap kelompok 'Arisan Seleb'. Hasil penelitian menunjukkan bahwa arisan yang awalnya tumbuh dalam lingkungan kecil terbatas dalam lingkungan PKK dengan nilai sosial dan gotong-royong yang lekat, berubah menjadi sebuah gaya hidup. Arisan tidak lagi tempat berkumpul bersilaturahmi 
dalam lingkungan terbatas dengan angsuran yang disesuaikan dengan kemampuan terbawah anggotanya, tapi telah berubah menjadi gaya hidup dimana berkembang pula di dalamnya fashion, konsumsi, dan presentasi kelas menengah atas. Di luar itu, dalam kelompok arisan masa kini tersebut, relasi kuasa tumbuh dan terjalin dengan baik. Ketua menjadi individu yang karena soft power mampu mengendalikan anggota kelompok, dimana kuasa tersebut diterima tanpa secara perlahan, tapi pasti dan kuat.

\section{Daftar Pustaka}

Asiz, Rangi Faridha. 2008 "Fenomena Gated Community di Perkotaan”.Thesis. Jakarta Universitas Indonesia.

Assael, H. $1998 \quad$ Consumer Behavior and Marketing Action 6th edition. New York : International Thomson Publishing.

Barker, Chris. 2004 The Sage Dictionary of Cultural Studies. London. SAGE Publications.

Baudrillard, Jean. 1998 The Consumer Society. London. Sage Publication

Chua, Beng Huat. 2012 Structure, Audience and Soft Power in East Asian Pop Culture.Hongkong. Hong Kong University Press

Chua, Beng Huat. 2000 Consumption in Asia, Lifestyle and Identities. London and New York: Routledge

Cresswell, John. 2003Research Design: Qualitative and Mixed Approaches. Sage Publication.

Fromm, Erich. 2005. On Being Human. Continuum: New York dan London. Routlledge.
Geertz, Clifford. 1962 "The Rotating Credit Association: A "Middle Rung" in Development". The journal of anthropology. Vol. 45, No. 3 (Nov 2006).

Giddens, Anthony. $1991 \quad$ Modernity and Self - Identity: Self and Society in the Late Modern Age. California. Stanford University Press.

Goffman, Erving. 1959. Presentation of Self in Everyday Life.New York: Doubleday Anchor Books.

Haryatmoko. 2013 "Masyarakat

Konsumeris dan Tatanan Tanda" Ringkasan buku Jean Baudrillard, La Societe de Consommation, 1970. Yogyakarta.

Heryanto, Ariel (ed). 2012 Budaya Populer Di Indonesia Mencairnya Identitas Pasca Orde Baru (terj). Yogyakarta. Jalasutra Yogyakarta.

Hospes, Otto. 1992 "People That Count: The Forgotten Faces of Rotating Saving and Credit Associations In Indonesia". The Journal of Anthropology. Vol. 16. No. 4. PP 371-441. 
Niehof, Anke. 1998 "The Changing Lives of Indonesian Woman Contained Emancipation under Pressure". The journal of Anthropogy. Vol. 154, No. 2. PP. 236-258.

Nova, Setyaningrum. 2012 "Perempuan dan Keperempuanan : Analisis Posfeminisme Terhadap Celebrity Shopper dan Confessions of a Shopaholic".Thesis.Yogyakarta - Universitas Gadjah Mada. Yogyakarta

Paterson, Mark. 2006 Consumption and Everyday Life. New York: Routledge.

Pinches, Michael (ed). 1999 Culture and Privilege in Capitalist Asia. London and New York: Routledge
Widhyharto, Derajat S. 2009 "Komunitas Berpagar; Antara Inovasi Sosial dan Ketegangan Sosial”.Jurnal Ilmu Sosial dan Politik. Vol. 13. No. 2. (204230). Yogyakarta. Universitas Gadjah Mada.

Youn-Mee, Cho. 1997 "Gaya Hidup dan Budaya Konsumen: Kasus Konsumen Galeria di Yogyakarta”. Thesis. Yogyakarta. Universitas Gadjah Mada.

\section{Internet}

http://ugm.ac.id/id/berita/9598/bankdu nia/prediksikan/pertumbuhan ekonomi Indonesia 2015. Diunduh pada 3 Maret 2015.

http://jakarta dalam angka.com/. Diunduh pada 10 Januari 2015 